\title{
Using Self-Determination Theory (SDT) to Investigate the Relationship between Organizational Commitment, Happiness and Work Engagement in Service Industry
}

\author{
Azzam A. Abou-Moghli ${ }^{1}$ \\ ${ }^{1}$ Department of Business Administration, Faculty of Business, Applied Science Private University, Amman, Jordan \\ Correspondence: Azzam A. Abou-Moghli, Department of Business Administration, Faculty of Business, Applied \\ Science Private University, Amman, Jordan. E-mail: a_aboumoghli@yahoo.com
}

Received: October 28, 2018

Accepted: November 27, 2018

Online Published: December 3, 2018

doi:10.5430/jbar.v8n1p29

URL: https://doi.org/10.5430/jbar.v8n1p29

\begin{abstract}
The economic competition is increasing day by day on both local and international level; therefore, it becomes the duty of organization to balance these processes along with job security. The study aimed to use the Self Determination Theory (SDT) to evaluate the relationship between work engagement, happiness and organizational commitment. A quantitative research design was used to conduct the study, selecting 317 individuals working in three telecommunications companies (Orange, Zain, and Umniah). Regression analysis and Chi square analysis were carried out on the data collected through the questionnaire survey. The results showed a significant relationship between organizational commitment, work engagement and happiness. The Self Determination Theory (SDT) was also found to be relevant in evaluating the factors that are responsible for affecting the behavior of employees towards the organization. The study provides significant knowledge to practitioners in evaluating factors that increase job dissatisfaction or job insecurity among employees that leads to a reduction in the level of work commitment and engagement.
\end{abstract}

Keywords: organizational commitment, self determination theory, work engagement, happiness, service industry

\section{Introduction}

Workforce plays an important role in achieving the strategic goals of an organization. Employees implement their knowledge and expertise in a particular area, which determines the future success of an organization. To achieve success, job satisfaction, commitment and loyalty to the company are considered to be the most important aspects in this regard (Pološki Vokic and Hernaus, 2015; Agu, 2015). Such that, the success of businesses greatly depends on the capital generated by humans. Thus, work engagement and self-efficacy are important factors in creating a positive outlook in the records of the organization (Agu, 2015). Therefore, a strong relationship between organizational commitment and employee engagement can have a significant and positive impact on the overall performance of the organization. The physical and emotional engagement with the work can impose a positive influence on the productivity and employee's happiness; therefore, the workplace behaviors such as commitment, job satisfaction and engagement can significantly benefit the company (Pološki Vokic and Hernaus, 2015).

Despite of the advantages of the aforementioned factors, there are several antecedents of organizational commitment, happiness and job loyalty. Such that, organizations face a number of challenges during downsizing, restructuring, and reengineering process; thus, provoking job insecurity among employees (Agu, 2015; Ugboro, 2016). Several studies have mentioned a positive and significant relationship between job commitment and job insecurity (Vujičić et al., 2015; Furaker and Berglund, 2014; Ugboro, 2016). Other problems reported are bullying in the workplace, which further reduced the work engagement of employees in the organization (Park and Ono, 2017). These factors belittle employees; thus, such processes can have a negative influence on both job commitment and physical health of the employees. It is, thus, the duty of the organization to improve the process of work commitment and job satisfaction by providing at least the basic necessities and protection to the employees in the workplace (Park and Ono, 2017).

Self-determination theory defines personality in the context of social behavior and human motivation. The theory is empirically derived theory, based on being controlling and autonomous, and motivation (Deci and Ryan, 2011). The theory is largely based on defining motivation and human personality and explain how individuals interact with each other and how they react to their social environment. A number of intrinsic and extrinsic motivations are being 
considered in the theory, which explain why human behave in a certain way and what are the factors that provoke such behavior (Legault, 2017). The core of the theory is based on the psychological needs of an individual, i.e. relatedness, autonomy and competence. Moreover, the theory also explains the role of these factors in increasing the level of self-determined motivation among such individuals (Legault, 2017). Furthermore, the theory also explains the influence of social and cultural aspects on facilitating or stripping down the psychological needs of individuals (Legault, 2017). The theory has been applied in various fields of life, such as, relationships, education, parenting, developmental, and exercising (Van den Broeck, Vansteenkiste and De Witte, 2008).

As market demands and job nature are changing, the psychological needs of the individual are also changing (Olafsen et al., 2017). Society, organization and employees are equally influenced by these psychological needs, thus, SDT discusses how these psychological needs trigger works-related stress among employees. The frustration associated with the increased demands of psychological needs, increases the level of work-related stress, as discussed by Olafsen et al. (2017). However, additional earning and psychological satisfaction also plays an important role, as discussed by Landry et al. (2016). To this end, it can be explained that this theory can be fruitful in discussing the relationship between organizational commitment, happiness and work engagement. The three factors are interlinked and are motivated or thwarted by extrinsic and intrinsic factors; therefore, the theory can help in analyzing the factors affecting and influencing the motivation of the individual towards their work.

Deci, Olafsen and Ryan (2017) described SDT as a theory, which can help in the development of policies and practices with respect to the workplace and organization. Wiedemann (2016) evaluated employee engagement with the help of SDT and concluded that employee engagement is driven by three factors, namely; relatedness, autonomy and competence, which are the pillars of SDT. On the other hand, Dulagil (2012) also reported that the items of self-determination theory can be used to describe the organizational commitment, job happiness and work engagement among employees. Therefore, the following hypotheses can be generated;

The study holds significance since it enlightens the motivational factors that increases work commitment, job loyalty and job happiness among employees. On the other hand, the study also highlights the factors, which creates job insecurity among employees; therefore, leading them to be less loyal to their jobs. In this advanced market, where organizations are taking extreme steps to enhance their skilled workforce; it will be a dilemma for a firm to lose its employees due to job insecurity. To this end, the following study contributes to the literature present on the current topic of research and it also provides a deep understanding of organizational commitment, work engagement and happiness among employees. Therefore, the study aims to evaluate self-determination theory (SDT) to investigate the relationship between organizational commitment, happiness and work engagement among employees in the service industry. SDT provides the basic understanding of the background along with its effectiveness on the current situation.

The study has postulated that satisfying the psychological demands competence, autonomy, and relatedness at work drives people to experience high levels of psychological well-being and happiness in the context of this study and considering the self-determination theory. The study has extended this theoretical model for proposing that the happiness of people at service industry consequently drives to increased positive organizational consequences. Likewise, the present study has proposed a model to examine whether happiness and work engagement can forecast organizational commitment considering SDT as a theoretical foundation. In Jordan, there have been lesser extent of studies on levels of engagement and the commitment of service industry with their employees. These studies have indicated that an employee can observe work engagement as a phenomenon associated to happiness, which is a determinant to positive organizational consequences. In addition, work engagement is observed as a determinant of organizational commitment. Though, no studies have been conducted previously to examine the relationship between organizational commitment, work engagement, and happiness at the service industry. Thereby, there is a dire need to research on the relationship between organizational commitment, happiness, and work engagement to add to the current body of knowledge regarding positive psychology and the significance of positive states at service industry as they influence positive organizational consequences. Additionally, there has been little research on whether organizational commitment can be predicted through happiness and work engagement. Thereby, this study aims to address this gap and proposed following hypotheses based on a review of literature.

$H_{0}$ : Self-Determination theory can be positively used to determine organizational commitment, happiness and work engagement.

$H_{l}$ : Self-Determination theory cannot be used to determine organizational commitment, happiness and work engagement. 


\subsection{Aims and Objectives}

The study investigates the relationship between organizational commitment, happiness and work engagement in the service industry. The factors that influence work engagement, happiness and organizational commitment are discussed in the following study.

\subsection{Research Questions}

Question 1: What are the factors that influence organizational commitment, happiness and work engagement?

Question 2: How can job insecurity influence organizational commitment, happiness and work engagement?

Question 3: How can Self-Determination Theory (SDT) explains organizational commitment, happiness and work engagement?

\section{Materials and Methods}

\subsection{Research Design}

This quantitative study has undertaken a cross-sectional research design to address the gap and to achieve the proposed objectives. The rationale for applying a cross-sectional research design was to investigate the relationship between organizational commitment, work engagement, and happiness at the service industry in Jordan. In addition, this study has aimed to determine the causal effect of organizational commitment, happiness, and work engagement in achieving positive organizational consequences. Likewise, a non-probabilistic sampling technique has been used to collect the data from the desired population. It is a most useful type of convenience sampling, which allows a researcher to select participants based on the convenience and ease of participants. According to (Huysamen, 1994), non-probability sampling is used because it is less complicated, more economical, and less time consuming.

\subsection{Sample Size and Population}

The study has targeted its reach toward the telecommunication industry in Jordan. According to the Export.Gov (2018), a total of 1783 employees are currently working in three big telecommunication companies such as Orange, Zain, and Umniah. A sample size calculator has been used to determine the sample size of the study, considering 5\% confidence level, population size 1783 and $95 \%$ power size. Based on the proposed elements, the study has calculated a sample of 317 from three telecommunication companies (Orange, Zain and Umniah) in Jordan. The sample showed great interest in participating in the study, since employees believed that organizational commitment, happiness and work engagement were often influenced due to a number of factors. The sample included both men and women belonging to different cultural backgrounds.

\subsection{Instrument}

A questionnaire survey was conducted to collect information from the sample of the study. The questionnaire was divided into four sections and was manually administered to the sample size. Section A of the questionnaire was based on the demographic details; whereas, Section B was based on the Well-being Questionnaire to evaluate happiness in the workplace. The Well-Being Questionnaire was designed in 1982 by the World Health Organization (WHO) and was aimed at measuring anxiety, depressed mood and several other factors that influence the positive well-being of the individual (Bradley, 1994). Section C included The Utrecht Work Engagement Scale to discuss work engagement among employees. The scale was first developed in 2002 by Schaufeli and Bakker (2003). Lastly, section D evaluates organizational commitment through a 7-point Likert scale.

\subsubsection{Organizational Commitment}

The Organizational Commitment Questionnaire was prepared to evaluate organizational commitment among employees. The questionnaire was based on a 7-point Likert scale ( 0 -strongly disagree - 6-strongly agree). The questionnaire was divided in three scale items, namely; affective commitment, continuance commitment and normative commitment. Each of the scale items consisted of 5 variables which were rated through the 7-point Likert scale. The affective, continuance, and normative organizational commitment of the participants have been measured through the organizational commitment questionnaire (Allen \& Meyer, 1990). The different types of organizational commitment in the organizational commitment questionnaire has been measured through these three subscales. The reliability of the three subscales of the organizational commitment questionnaire has been presented using Cronbach Alpha. The Cronbach Alpha coefficients for the scales were 0.77 for the continuance commitment subscale, 0.81 for the normative commitment subscale, and 0.85 for the continuance commitment subscale. In addition, the reliability for the organizational commitment questionnaire is reliable as a whole. 


\subsubsection{Happiness}

The Well-Being Questionnaire was used to evaluate happiness among employees. The subscale items included in the questionnaire were negative (4 items), energy (4 items) and positive (4 items). Each subscale item was further divided into items which represented the level of happiness among employees. Bradley (1994) has proposed the well-being questionnaire to measure the happiness of people. The well-being questionnaire detects psychological well-being in people with a chronic somatic illness. Though, it has further been used as a measure of well-being in the public. A 5-point Likert-type scale has been used to score the well-being questionnaire for measuring depression, positive well-being, energy, and anxiety. The Cronbach Alpha coefficient for the overall well-being questionnaire scales was 0.94 .

\subsubsection{Work Engagement}

The Utrecht Work Engagement Scale was used to collect data with respect to work engagement. The questionnaire was divided into seventeen items which were then rated by the employees from a 7-point Likert scale. The rating on the scale started from 0-never, 1-almost never, 2-rarely, 3-sometimes, 4-often, 5-very often, and 6-always. Schaufeli et al (2002) have proposed the Utrecht Work Engagement Scale as a measure of work engagement. Vigour, absorption, and dedication were the three dimensions of the work engagement commonly used in the well-being questionnaire. A 7-point frequency scale has been used to measure the subscales of The Utrecht Work Engagement Scale. The Cronbach Alpha coefficients for the three subscales were 0.71, 0.79, and 0.83, respectively.

\subsection{Data Collection}

A self-administered questionnaire has been designed based on the three instruments mentioned above to collect the data from selected sample in the study. The researcher has distributed a total of 400 questionnaires to the employees after taking approval from the CEO of all three telecommunication companies. A research consent form along with a study proposed objective was also provided to each employee for understanding the consent to collect the data from them. Out of 400 questionnaires, a total of 317 questionnaires were returned properly filled, 50 questionnaires were partially filled and 33 were never returned at all. Completely filled questionnaires were selected for the study while rest of the questionnaires were excluded.

\subsection{Data Analysis}

The data has been analyzed using Statistical Package for Social Sciences (SPSS) version 23.0. The study has used both descriptive and inferential statistics to analyze the data collected from the participants. For descriptive analysis, frequencies and percentages were presented for the demographic variables, which include gender, age, marital status, work experience, and qualification. Likewise, inferential statistics were presented to show the relationship between the proposed constructs of the study. In addition, multiple regression analysis was used to determine the causal effect of work engagement, happiness, and organizational commitment in achieving positive organizational consequences. Moreover, chi square test was carried out to evaluate the relationship between organizational commitment, happiness and work engagement. The significance measure for all these inferential tests was based on 5\% confidence interval.

\section{Results}

The demographic details of participants are presented in Table 1. A total of $90.2 \%$ male and $9.8 \%$ female employees participated in the study. The findings have shown that $37.5 \%$ employees were experienced (6-10 years) while $22.4 \%$ employees were less experience. 
Table 1. Demographic Details

\begin{tabular}{lll}
\hline Variables & Frequency & Percent \\
\hline Gender & 286 & 90.2 \\
Male & 31 & 9.8 \\
Female & & \\
Age & 24 & 7.6 \\
24 years and younger & 65 & 20.5 \\
25-35 years & 24 & 7.6 \\
36-45 years & 82 & 25.9 \\
46-55 years & 122 & 38.5 \\
56 years or older & & \\
Marital Status & 120 & 37.8 \\
Single & 38 & 11.9 \\
Divorced & 20 & 6.3 \\
Widowed & 139 & 43.8 \\
Married & & \\
Work Experience & 71 & 22.4 \\
Fewer than five years & 119 & 37.5 \\
6-10 years & 64 & 20.2 \\
11-20 years & 63 & 19.9 \\
More than 20 years & & 24.3 \\
Qualification & 77 & 31.2 \\
Matriculation & 99 & 18.3 \\
Diploma & 58 & 26.2 \\
Degree & & \\
Postgraduate degree & & \\
\hline Table shows & & \\
\hline
\end{tabular}

Table 2 shows information regarding the chi square value of work engagement. All the seventeen items were found to be significantly related to gender. Overall, the findings have reported that employees were more concerned towards the work engagement and; therefore, mentioned a significant association of each sub-item of work engagement towards their job security. Among these sub-items, inspiration, enthusiasm, motivation, encouragement, and mental wellness were commonly reported sub-items associated to their positive work engagement. 
Table 2. Chi Square for Work Engagement

\begin{tabular}{|c|c|c|c|}
\hline Variables & Gender & & Chi square \\
\hline & Male & Female & \\
\hline $\begin{array}{l}\text { At my work, I feel bursting with } \\
\text { energy }\end{array}$ & 0 & 7 & 0.000 \\
\hline $\begin{array}{l}\text { I find the work that I do full of } \\
\text { meaning and purpose }\end{array}$ & 70 & 31 & 0.000 \\
\hline Time flies when I'm working & 43 & 0 & 0.004 \\
\hline $\begin{array}{l}\text { At my job, I feel strong and } \\
\text { vigorous }\end{array}$ & 0 & 9 & 0.000 \\
\hline I am enthusiastic about my job & 100 & 31 & 0.001 \\
\hline $\begin{array}{l}\text { When I am working, I forget } \\
\text { everything else around me }\end{array}$ & 0 & 8 & 0.002 \\
\hline My job inspires me & 13 & 31 & 0.001 \\
\hline $\begin{array}{l}\text { When I get up in the morning, I } \\
\text { feel like going to work }\end{array}$ & 0 & 1 & 0.000 \\
\hline $\begin{array}{l}\text { I feel happy when I am working } \\
\text { intensely }\end{array}$ & 128 & 31 & 0.005 \\
\hline $\begin{array}{l}\text { I am proud on the work that I } \\
\text { do }\end{array}$ & 127 & 31 & 0.001 \\
\hline I am immersed in my work & 178 & 31 & 0.000 \\
\hline $\begin{array}{l}\text { I can continue working for very } \\
\text { long periods at a time }\end{array}$ & 11 & 0 & 0.003 \\
\hline To me, my job is challenging & 78 & 31 & 0.001 \\
\hline $\begin{array}{l}\text { I get carried away when I'm } \\
\text { working }\end{array}$ & 0 & 8 & 0.000 \\
\hline $\begin{array}{l}\text { At my job, I am very resilient, } \\
\text { mentally }\end{array}$ & 98 & 31 & 0.002 \\
\hline $\begin{array}{l}\text { It is difficult to detach myself } \\
\text { from my job }\end{array}$ & 9 & 31 & 0.000 \\
\hline $\begin{array}{l}\text { At my work I always persevere, } \\
\text { even when things do not go well }\end{array}$ & 0 & 14 & 0.001 \\
\hline
\end{tabular}

Table 3 shows the results obtained for chi square analysis for happiness. All items were found to be significant with gender. The findings have further revealed that employees were always felt a lack of happiness in the organization and this eventually leads to negative work engagement, organizational commitment and job security. 
Table 3. Chi Square for Happiness

\begin{tabular}{|c|c|c|c|}
\hline Variables & Gender & & Chi square \\
\hline & Male & Female & \\
\hline $\begin{array}{l}\text { I have crying spells or } \\
\text { feel like it }\end{array}$ & 117 & 31 & 0.000 \\
\hline $\begin{array}{l}\text { I feel downhearted and } \\
\text { blue }\end{array}$ & 2 & 31 & 0.002 \\
\hline $\begin{array}{l}\text { I feel afraid for no reason } \\
\text { at all }\end{array}$ & 0 & 20 & 0.001 \\
\hline $\begin{array}{l}\text { I get upset easily or feel } \\
\text { panicky }\end{array}$ & 68 & 31 & 0.000 \\
\hline $\begin{array}{l}\text { I feel energetic, active or } \\
\text { vigorous }\end{array}$ & 28 & 12 & 0.000 \\
\hline I feel dull or sluggish & 11 & 4 & 0.001 \\
\hline $\begin{array}{l}\text { I feel tired, worn out, } \\
\text { used up or exhausted }\end{array}$ & 8 & 31 & 0.000 \\
\hline $\begin{array}{l}\text { I have been waking up } \\
\text { feeling fresh and rested }\end{array}$ & 107 & 0 & 0.001 \\
\hline $\begin{array}{l}\text { I have been happy, } \\
\text { satisfied or pleased with } \\
\text { my personal life }\end{array}$ & 75 & 0 & 0.000 \\
\hline $\begin{array}{l}\text { I have lived the kind of } \\
\text { life I wanted to }\end{array}$ & 58 & 0 & 0.002 \\
\hline $\begin{array}{l}\text { I have felt eager to tackle } \\
\text { my daily tasks or make } \\
\text { new decisions }\end{array}$ & 59 & 0 & 0.001 \\
\hline $\begin{array}{l}\text { I have felt I could easily } \\
\text { handle or cope with any } \\
\text { serious problem or major } \\
\text { change in my life }\end{array}$ & 72 & 25 & 0.000 \\
\hline
\end{tabular}

Table 4 shows the results obtained for chi square analysis of organizational commitment. All the items were found to be significant with gender. Employees have mentioned that their organizational commitment is positively influenced by recognition and appraisal, which helps them to understand the problems and concerns present in the organization as their own. However, the role of management towards employees lacks positivity, which allows employees to switch their jobs.

Table 4. Chi Square for Organizational Commitment

\begin{tabular}{lll}
\hline Variables & Gender & Chi Square \\
\hline $\begin{array}{l}\text { I would be very happy to } 57 \\
\text { spend the rest of my } \\
\text { career with this } \\
\text { organization. }\end{array}$ & 31 & 0.000 \\
$\begin{array}{l}\text { I enjoy discussing my } 0 \\
\text { organization with people } \\
\text { outside it. }\end{array}$ & 6 & \\
I really feel as if this 70 & 0 & 0.001 \\
organization's problems \\
are my own.
\end{tabular}


I think that I could easily

0

0.000

become as attached to

another organization as I

am to this one.

I do not feel like 'part of 53

the family' at my

organization.

I am not afraid of what 0

might happen if I quit

my job without having

another one lined up.

It would be very hard for 0

me to leave my organization right now, even if I wanted to.

Too much in my life 28

would be disrupted if I

decided I wanted to leave my organization now.

It wouldn't be too costly 0

for me to leave my organization now.

Right now, staying with 0

my organization is a matter of necessity as much as desire.

I think that people these days move from company to company too often.

I do not believe that a 0 person must always be loyal to his or her organization

Jumping from 23
organization to
organization does not
seem at all unethical to
me.
One of the major reasons 16
I continue to work for
this organization is that I
believe that loyalty is
important and therefore
feel a sense of moral
obligation to remain.
If got another offer for 0
a better job elsewhere, I
would not feel it was
right to leave my
organization

The impact of work engagement, happiness and organizational commitment to the job security of employees has been examined from regression analysis (Table 5). The findings have shown a positive and significant impact of 
work engagement $(p=0.001)$ and organizational commitment $(p=0.029)$ on job security. However, a negative but significant impact of happiness was found on the job security, which means that if employees lack happiness their job security will be at high risk $(\mathrm{p}=0.000)$.

Table 5. Regression Analysis

\begin{tabular}{|c|c|c|c|c|c|c|c|}
\hline \multirow[t]{2}{*}{ Model } & \multicolumn{2}{|c|}{$\begin{array}{l}\text { Unstandardized } \\
\text { Coefficients }\end{array}$} & $\begin{array}{l}\text { Standardized } \\
\text { Coefficients }\end{array}$ & $\mathbf{R}$ & R square & $\mathbf{t}$ & Sig. \\
\hline & B & $\begin{array}{l}\text { Std. } \\
\text { Error }\end{array}$ & Beta & & & & \\
\hline Constant & 0.812 & 0.051 & - & 16.061 & 0.829 & 16.061 & 0.000 \\
\hline $\begin{array}{l}\text { Work } \\
\text { Engagement }\end{array}$ & 0.336 & 0.050 & 1.676 & & & 6.736 & 0.001 \\
\hline Happiness & -0.349 & 0.019 & -2.010 & & & -18.674 & 0.000 \\
\hline $\begin{array}{l}\text { Organizational } \\
\text { Commitment }\end{array}$ & 0.108 & 0.049 & 0.653 & & & 2.196 & 0.029 \\
\hline
\end{tabular}

\section{Discussion}

The results showed that organizational commitment, work engagement and happiness showed a positive relationship between these variables. The results were found to be in support of Self Determination Theory (SDT) which is a combination of all these variables. Therefore, it can be concluded that work engagement, happiness and organizational commitment can change with respect to time and conditions. The results of the study were found to be consistent with the findings of Vorina et al. (2017). The study showed that motivation plays an important role in improving the performance of employees at the workplace. It was found that those employees who are well-motivated to perform better, as compared to those employees who are not well-motivated. Moreover, the study also discussed the relationship between employee engagement and business performance. Therefore, the more enthusiastic the employee, the more business performs better.

The results have supported the first hypothesis, which indicates that there is a relationship between organizational commitment, happiness, and work engagement. The results have shown that there is a positive relationship between affective, normative, and continuous organizational commitment and work engagement, and happiness. Another study discussed the relationship between organizational commitment, employee engagement and career satisfaction. The study stated a positive relationship between organizational commitment, employee engagement, and career satisfaction. However, the results of the study found that organizational commitment was deeply related to employee engagement; whereas, career satisfaction was more related to the organizational commitment. On the other hand, the study also showed additional information, employees who were provided with learning opportunities showed more work engagement and commitment level with the organization.

The results were also found to be consistent with Masese et al. (n.d). The study showed that the employee engagement can be achieved by engaging employees in the process of decision-making and in taking opinions. To foster employee engagement, it is necessary for the organizations treat their employees equally without any gender or qualification bias. Other factors that enhance employee engagement includes; training, conducting seminars, team building, career growth and development, and suitable working environment. The study also suggested that those organizations where employee engagement is not adequately controlled; employees start to disengage themselves with the organization thus reducing their level of commitment and engagement. Other studies conducted by Goldenhuys, Laba and Venter (2014), Taris and Schaufeli (2015) and De Wet (2015) also concluded similar results.

The results have completely supported the first and second hypotheses of this study and showed that happiness, organizational commitment, and work engagement positively and significantly achieve positive organizational consequences. The study has revealed that affective organizational commitment was the most predictive dimension of the work engagement whereas other variables were kept constant. Happiness was the second most predictive element of the well-being as measured from both Chi-square and multiple regression analysis. Thereby, this study has presented an important and valuable contribution to the research stream by providing significant effect of happiness, work engagement, and organizational commitment in achieving positive organizational consequences. Due to little research on this specific context, this finding has extended the current body of knowledge on positive psychology in the context of service industry as happiness being a predictor of well-being plays an important part in forecasting the positive organizational result of organizational commitment. The study has found very little evidence 
that directly examines happiness as a predictor of work engagement specifically in the service industry in Jordan. Thereby, the study has suggested that the results from this specific study provide valuable insights into a potential relationship between the three constructs.

Although, the study provides fruitful results; however, it has some limitations. A cross-sectional research design has been used in this study while a longitudinal research design was being opposed. Thereby, the findings of this study cannot provide causality between the variables. Secondly, a non-probability convenience sampling method has been used, which may lack generalizability to all employees working in all three telecommunication companies in Jordan. Thirdly, a self-administered questionnaire was used to collect data, which can influence the validity and reliability of the data as participants might have answered the questions to provide more socially accepted responses as compared to the ones that reveal actual opinions. Fourthly, the study only focused on one particular sector of industry which can limit its results. Therefore, future studies are suggested to include more sectors to produce more generalized results. Future studies can include bigger sample size from different regions to evaluate the factors, influencing work engagement of employees.

\section{Conclusion}

Self Determination Theory (SDT) discussed the psychological factors that can significantly influence the performance of an individual at various levels. Such that, work engagement, happiness and the organization's commitment are some factors that can both positively and negatively influence the performance of an individual? Thus, the results of the current study indicated a positive relation between organizational commitment, work engagement and happiness with respect to the Self Determination Theory (SDT). The study can provide significant knowledge to practitioners in evaluating factors that increases job dissatisfaction or job insecurity among employees that leads to reduction in the level of work commitment and engagement. It is the duty of the organization and researchers to develop strategies and methods to overcome these factors leading to financial harm to the organization. The organizations must be made aware of the financial harm that can have a significant impact on the business performance of the organization.

It has been suggested for future studies to use a cross-functional type of research design. In contrast, more longitudinal studies should be conducted with large samples to predict causal relations between the constructs more appropriately and accurately. This element will significantly lead to outcomes that are more accurate and generalizable. Several studies need to validate research for assuring the generalizable findings in assorted work contexts. The literature review has shown that there has been sufficient evidence in the context of positive psychology and specifically on the happiness, organizational commitment, and happiness concepts. In contrast, the association between these three concepts require a dire attention of researchers in Jordan.

Individuals are spending most of their lives in their working environment. Thereby, this study is appropriate as it addresses the concern of happiness in the workplace setting and its association to other organizational subscales such as organizational commitment and work engagement. The current study has accounted on the forecasted value of work engagement and happiness for organizational commitment. Thereby, the study findings will benefit all stakeholders in the workplace setting. The existing study will assist organizations in improving organizational consequences and organizational commitment, in particular. It will also assist organizations in understanding the needs of workers, specifically their happiness levels and benefits they bring for happiness.

\section{Acknowledgement}

The author is very thankful to all the associated personnel in any reference that contributed in/for the purpose of this research.

\section{References}

Agu, O. L. (2015). Work engagement, organizational commitment, self-efficacy and organizational growth: A literature review. Information Impact: Journal of Information and Knowledge Management, 6(1), 14-29.

Bradley, C. L. A. R. E. (1994). The well-being questionnaire. Handbook of psychology and diabetes: A guide to psychological measurement in diabetes research and practice, 89-109.

De Wet, E. H. (2015). Employee engagement and satisfaction of self-determination needs: an exploratory study in the contract research sector (Doctoral dissertation).

Deci, E. L., Olafsen, A. H., \& Ryan, R. M. (2017). Self-determination theory in work organizations: the state of a science. Annual Review of Organizational Psychology and Organizational Behavior, 4, 19-43. https://doi.org/10.1146/annurev-orgpsych-032516-113108 
Dulagil, A. (2012). The relationship of employee engagement and wellbeing to organisational and student outcomes.

Export.Gov (2018). Information and Communication Technology. Jordan Country Commercial Guide.

Furaker, B., \& Berglund, T. (2014). Job insecurity and organizational commitment. RIO: Revista Internacional de Organizaciones, 13, 163-186.

Geldenhuys, M., Laba, K., \& Venter, C. M. (2014). Meaningful work, work engagement and organisational commitment. SA Journal of Industrial Psychology, 40(1), 01-10. https://doi.org/10.4102/sajip.v40i1.1098

Huysamen, G. K. (1994). Methodology for the social and behavioural sciences. Southern Book Publishers.

Landry, A. T., Kindlein, J., Trépanier, S. G., Forest, J., Zigarmi, D., Houson, D., \& Brodbeck, F. C. (2016). Why individuals want money is what matters: Using self-determination theory to explain the differential relationship between motives for making money and employee psychological health. Motivation and Emotion, 40(2), 226-242. https://doi.org/10.1007/s11031-015-9532-8

Legault, L. (2017). Self-determination theory. Encyclopedia of Personality and Individual Differences, 1-9. https://doi.org/10.1007/978-3-319-28099-8_1162-1

MASESE, J. N. Relationship between Employee Engagement and Organizations Commitment at the Kenyan Teachers Service Commission.

Olafsen, A. H., Niemiec, C. P., Halvari, H., Deci, E. L., \& Williams, G. C. (2017). On the dark side of work: A longitudinal analysis using self-determination theory. European Journal of Work and Organizational Psychology, 26(2), 275-285. https://doi.org/10.1080/1359432X.2016.1257611

Park, J. H., \& Ono, M. (2017). Effects of workplace bullying on work engagement and health: The mediating role of job insecurity. The International Journal of Human Resource Management, 28(22), 3202-3225. Deci, E. L., \& Ryan, R. M. (2011). Self-determination theory. Handbook of theories of social psychology, 1(2011), 416-433. https://doi.org/10.1080/09585192.2016.1155164

Pološki Vokić, N., \& Hernaus, T. (2015). The triad of job satisfaction, work engagement and employee loyalty-The interplay among the concepts. EFZG working paper series, (07), 1-13.

Schaufeli, W. B., \& Bakker, A. B. (2003). Utrecht work engagement scale: Preliminary manual. Occupational Health Psychology Unit, Utrecht University, Utrecht, 26.

Taris, T. W., \& Schaufeli, W. (2015). Individual well-being and performance at work: A conceptual and theoretical overview.

Ugboro, I. O. (2016). Influence of managerial trust on survivors' perceptions of job insecurity and organizational commitment in a post restructuring and downsizing environment. Journal of Behavioral and Applied Management, 4(3), 1077.

Van den Broeck, A., Vansteenkiste, M., \& De Witte, H. (2008). Self-determination theory: A theoretical and empirical overview in occupational health psychology. https://doi.org/10.1111/j.1464-0597.2009.00391.x

Vorina, A., Simonič, M., \& Vlasova, M. (2017). An Analysis of the Relationship between Job Satisfaction and Employee Engagement. Economic Themes, 55(2), 243-262. https://doi.org/10.1515/ethemes-2017-0014

Vujičić, D., Jovičić, A., Lalić, D., Gagić, S., \& Cvejanov, A. (2015). The relation between job insecurity, job satisfaction and organizational commitment among employees in the tourism sector in Novi Sad. Economic and Industrial Democracy, 36(4), 633-652. https://doi.org/10.1177/0143831X14527017

Wiedemann, C. S. (2016). Investigating Employee Engagement through a Self-Determination Theory Framework. 